\title{
Transarterial Embolization of Direct Carotid Cavernous Fistula by Coils
}

\author{
MOHAMED SHADAD, M.D.* and HAZEM NEGM, M.D.** \\ The Department of Neurosurgery, Faculty of Medicine, Tanta* and Menoufia** Universities
}

\begin{abstract}
Background: Type A CCFs (direct CCFs) usually resulting from tear in the carotid wall. Clinical presentations were due to increased venous pressure and presents by classic triad of exophthalmos, chemosis, and bruit. Cerebral angiography still the gold standard in diagnosis, classification and planning of treatment. Type A CCFs mandates endovascular intervention.

Aim of Study: The aim of this study to evaluate safety and efficacy of transarterial approach by using coils for treatment of direct CCFs.

Patients and Methods: This study conducted on all patients with direct carotid cavernous fistula admitted to Department of Neurosurgery, Tanta University between December 2010 and November 2016.

Results: Twelve patients including 10 male and 2 female, with a mean age of 33 years. All patients had symptoms and signs related to direct CCF. In 12 patients (100\%) complete obliteration of the CCF was achieved at control angiogram at the end of the procedure. ICA was preserved in 9 patients $(75 \%)$ while carotid occlusion in addition was done in 3 patients $(25 \%)$ without permanent morbidity or mortality.

Conclusions: Transarterial embolization of direct carotid cavernous fistula by coils is effective, safe technique and better alternative to balloons in the treatment of direct carotid cavernous fistula.
\end{abstract}

Key Words: Transarterial embolization - Direct carotid cavernous fistula-Coils.

\section{Introduction}

TYPE A CCFs (direct CCFs) represent an abnormally high flow arteriovenous communication between Internal Carotid Artery (ICA) and Cavernous Sinus (CS), usually resulting from tear in the carotid wall. In other types B, C \& D (indirect $\mathrm{CCF}$ ) there is activation of preexisting microscopic communications between dural arteries and venous sinuses [1]. Direct CCFs subdivided into 3 subtypes:

Correspondence to: Dr. Mohamed Shadad, The Department of Neurosurgery, Faculty of Medicine, Tanta University
High, intermediate, or low flow. In high-flow DCCFs, all the blood form the ICA entered the fistula without filling of intracranial vessels. In intermediate-flow DCCFs, both the fistula and intracranial vessels received blood from the ICA, and in the low-flow DCCFs only slow and sluggish filling of the cavernous sinus was apparent [2]

Clinical presentations were due to increased venous pressure of the cavernous sinus which transmitted anterior to ophthalmic veins and posterior to Inferior Petrosal Sinus (IPS). Increased orbital venous pressure presents by classic triad of exophthalmos, chemosis, and bruit. Diplopia due to irritation of III, IV, VI cranial nerves. Visual loss is the most dangerous due to retinal ischemia. Epistaxsis and intracranial hemorrhage due to increase of the venous pressure are the least common [3].

Pre-therapeutic evaluation include CT brain with bone window in different plans and $3 \mathrm{D}$ reconstruction. This will show basal skull fractures, intracranial hematomas. CT angiography sometimes is good assist in description of the fistula. MRI/ MRA brain could provide important information like dilatation of superior ophthalmic vein [4] Cerebral angiography still the gold standard in diagnosis, classification and planning of treatment in CCFs. Using high frame rate (7f/s) ipsilateral ICA examined with trial for localization of the site of fistula and determination of venous outflow. Testing contralateral ICA and vertebral artery to check presence of good collaterals if carotid occlusion is planned [5].

Treatment options include conservative manual carotid jugular compression, microsurgical and endovascular approaches. Sterotactatic radiosurgery is kept for indirect CCFs which failed with endovascular therapy. Revolution in the endovascular 
treatment of CCF started with introduction of detachable balloon by Serbinenko in 1974 [6] Recent advances in endovascular techniques achieved with refinements of microcatheters, microwires, balloons and coils in addition to improvement of image quality with the aid of new generations of angiography machines. To date, endovascular techniques became the state of art in $\mathrm{CCF}$ treatment.

Type A CCFs are less likely to resolve spontaneously and usually mandates endovascular intervention. Different endovascular techniques include trans-arterial, trans-venous (either retrograde or superior ophthalmic vein puncture) with occlusion of fistula site and keeping patency of ICA. When failed, occlusion of the ICA with fistula site in the presence of good collateral is an option [7].

\section{Aim of the work:}

The aim of this study to evaluate safety and efficacy of transarterial approach by using coils for treatment of direct CCFs as new approach for treatment instead of balloons.

\section{Patients and Methods}

\section{Patient population:}

Between December 2010 and December 2016, a total of 12 patients DCCFs were treated by endovascular transarterial approach at Department of Neurosurgery, Tanta University Hospitals. Of these patients, 10 were male and 2 were female, with a mean age of 33 years (range 15-55). All patients had history of head trauma including either closed head injury in 9 patients and penetrating head injury in 3 patients. All patients had symptoms and signs related to direct $\mathrm{CCF}$ including exophthalmos and chemosis in 12 patients $(100 \%)$, bruit in 10 patients $(83 \%)$, decreased visual acuity in 6 patients $(50 \%)$ including blindness on the affected eye in 2 patients and cranial nerve palsy in 4 patients (33\%).

\section{Diagnosis:}

CT brain with bone window showed Basal Skull Fractures (BSF), thickening of extra-ocular muscles, dilatation of Cavernous Sinus (CS), dilatation of Superior Ophthalmic Vein (SOV) and detection of proptosis. MRI poor in detection of bony details but more accurate in soft tissue details [8]. MRI show abnormal CS flow void, a finding specific to $\mathrm{CCF}$ [9].

Digital Subtraction Angiography (DSA) is the gold standard in diagnosis and planning of treatment of CCF. DSA can detect site of tear, flow rate and pattern of venous drainage. Balloon Occlusion Test (BOT) is mandatory in all cases even if carotid occlusion in not planned with assessment of contralateral carotid and vetertebral arteries to check collateral flow from ACOM \& PCOM also fow in ophthalmic artery according flow rate CCF subdivided into high, intermediate and low. In high flow CCF all blood from carotid pass through fistula, in intermediate flow CCF blood pass through fistula and to intracranial vessels and in low flow $\mathrm{CCF}$ slow filling of CS occur [2]

According venous drainage CCF may had anterior venous drainage through superior and inferior ophthalmic vein (SOV \& IOV), posterior venous drainage through superior and inferior petrosal sinuses (SPS \& IPS), superior venous drainage to cortical veins, inferior venous drainage to pterygoid plexus and finally could drain to contralateral CV through intercavernous connection [5] .

\section{Endovascular treatment:}

Under general anesthesia standard bilateral trans-femoral approaches were used. 7F guiding catheter was used to access ipsilateral ICA at the level of $\mathrm{C} 1$ and 5F diagnostic catheter was used to access contralateral ICA and vertebral artery for control. Test occlusion done first using $0.5 \mathrm{ml}$ non detachable silicone balloon in each case to check feasibility of ICA occlusion even if not planned. simultaneous appearance of veins of both hemispheres during venous phase was good indicator for success of test. Lag more than 4 seconds in appearance of veins on ipsilateral hemisphere indicate poor collateral supply and ICA occlusion must be avoided. Checking of direction of flow in ophthalmic and posterior communicating arteries was important as opposing flow can lead to stasis and blindness.

Under guidance of high definition roadmap and high resolution DSA, 0.14 braided, Demso compatible microcatheter guided by soft tip $0.14 \mathrm{mi}-$ crowire was used coaxially and entered through tear in the wall to Cavernous Sinus (CS) until achieving optimal position. Deployment of coils into CS was done until occlusion of fistula achieved. Frequent controls from ipsilateral and contralateral ICA was done during different stages of coiling to check occlusion and patency of ICA. Finally control from ipsilateral ICA, contralateral ICA, VA, ipsilateral ECA to check complete obliteration of fistula was done. Hypotension is not allowed during procedure or in the early post intervention period. Control CT brain is done routinely before discharge to ICU where patient 
kept for 24 hours. Patient transferred to ordinary room for another 24 hours before hospital discharge.

\section{Follow-up:}

Clinical evaluation was done immediately post intervention, at hospital discharge and at regular follow-up visits. MRI/MRA was done before hospital discharge and at 6 months to check stability of occlusion. DSA was done only in selected cases during period of follow-up.

\section{Results}

Imaging results:

CT brain with bone window showed BSF in 4 patients, dilatation of $\mathrm{SOV}$ in 10 patients. MRI brain showed dilatation of SOV in 10 patients and abnormal CS flow void in 8 patients. DSA detected that fistula in horizontal segment of cavernous carotid artery in 4 patients and vertical segment in 8 patients. According flow; 9 patients $(75 \%)$ had high flow CCF, 3 patients $(25 \%)$ had intermediate flow CCF and none of patients had low flow. According venous drainage; 9 patients had dominant anterior venous drainage, 2 patients had dominant posterior venous drainage and 1 patient had venous drainage to contralateral CS. Eight patients had passed BOT and 4 patients there was lag in the venous phase more than 4 seconds between both hemispheres and we consider this as end point to the test.

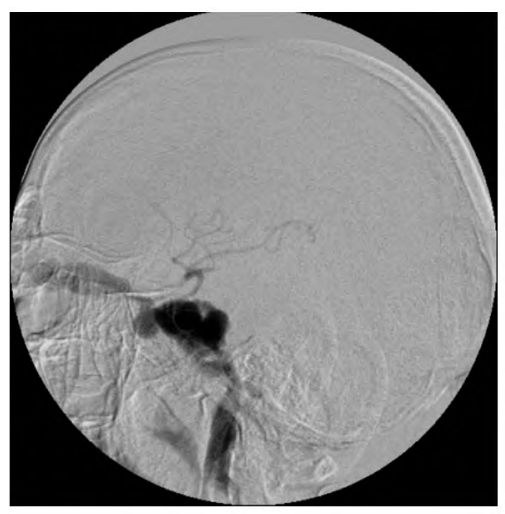

LT ICA LAT pre

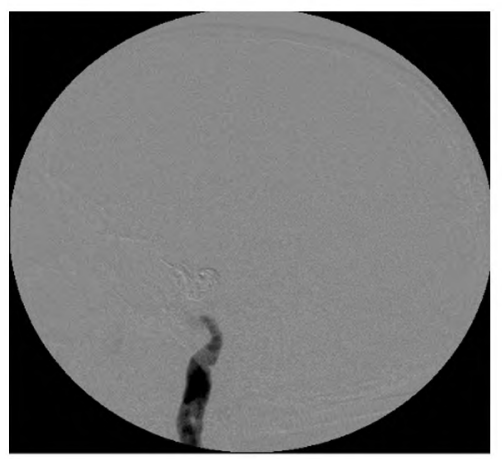

LT ICA post

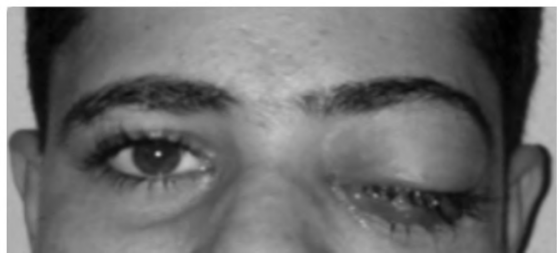

Pre-operative LT side proptosis

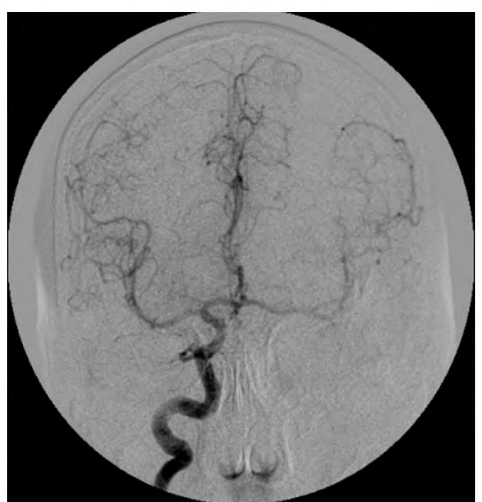

BOT: Arterial phase RT ICA AP

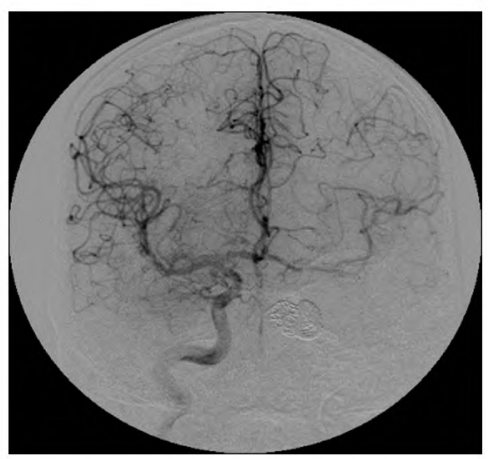

RT ICA post

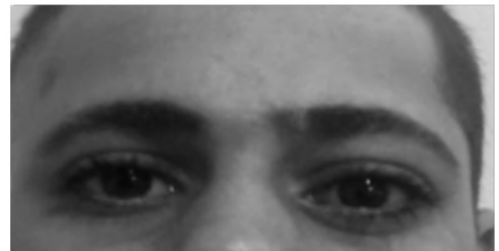

Improved proptosis after 1 month

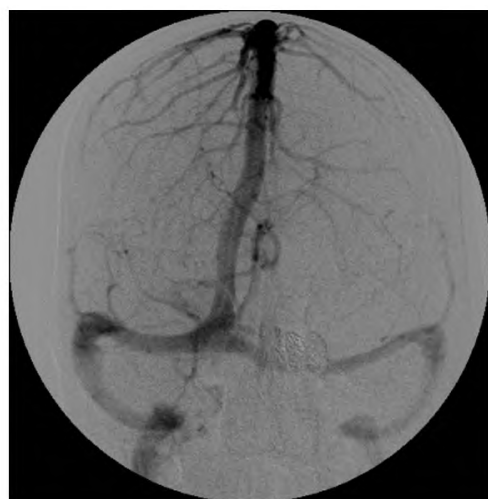

BOT: Venous phase RT ICA AP

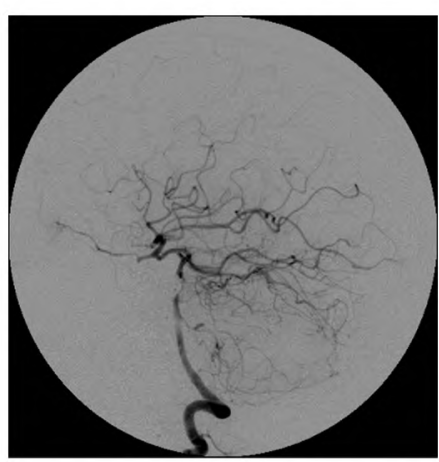

LT VA post

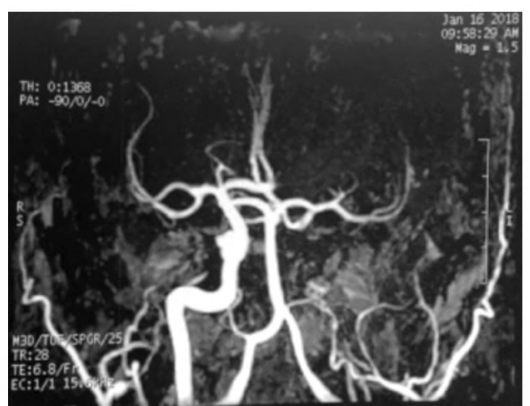

Follow-up MRA after 1 year

Case (1): Male patient, 17 years old, presented with LT direct CCF after road traffic accident. BTO done with good collateral supply, occlusion of CCF as well as ICA done. Improvement of proptosis achieved and stable occlusion of CCF at 1 year on follow-up MRA. 


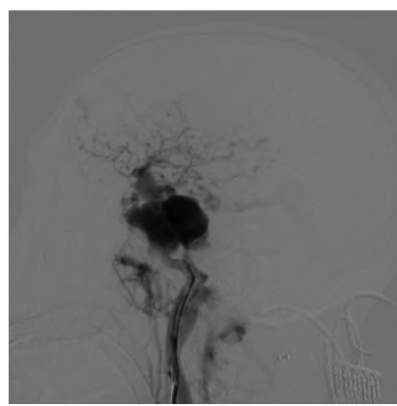

RT ICA AP pre

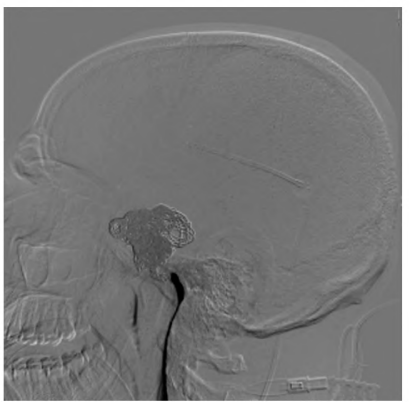

RT ICA AP post

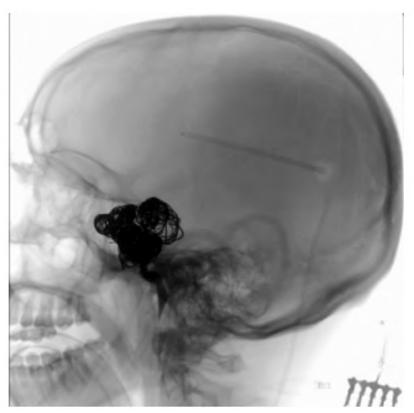

Fluroscopic image LAT (coil mass)

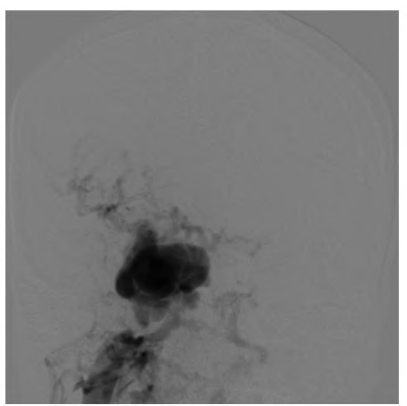

RT ICA LAT pre

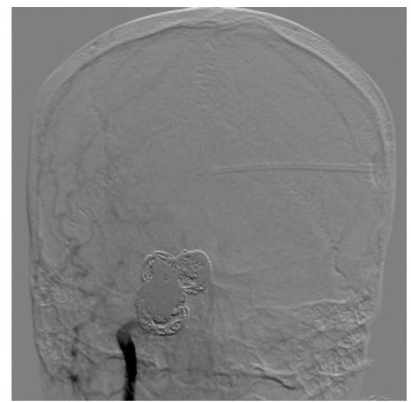

RT ICA LAT post

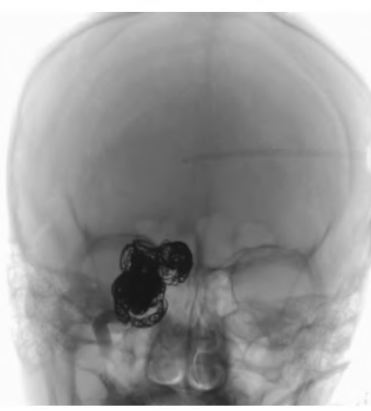

Fluroscopic image AP (coil mass)

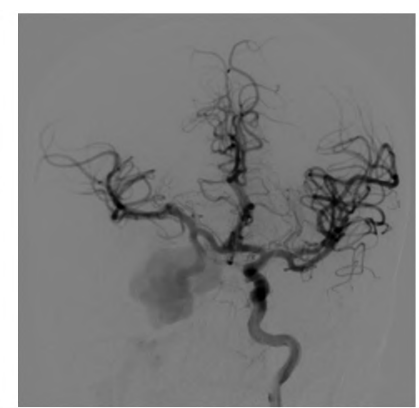

LT ICA AP pre

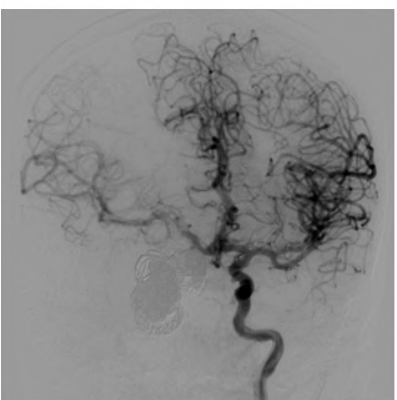

LT ICA AP post

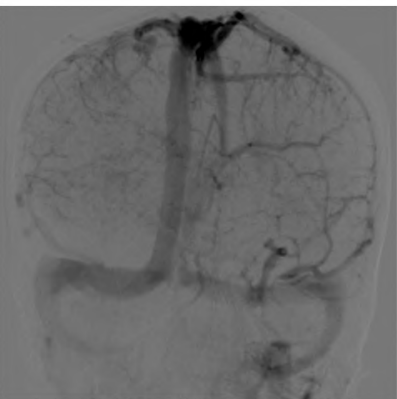

LT ICA (BTO) venous phase

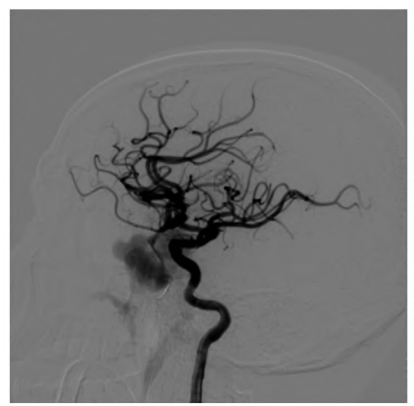

LT VA LAT pre

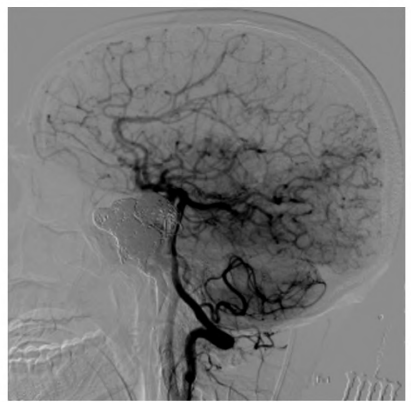

LT VA LAT post

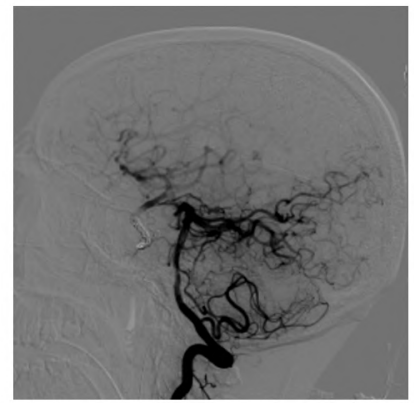

Occlusion of ICA proximal to ophthalmic A

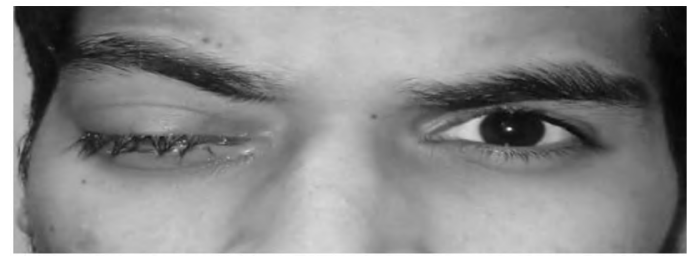

RT proptosis pre-operative

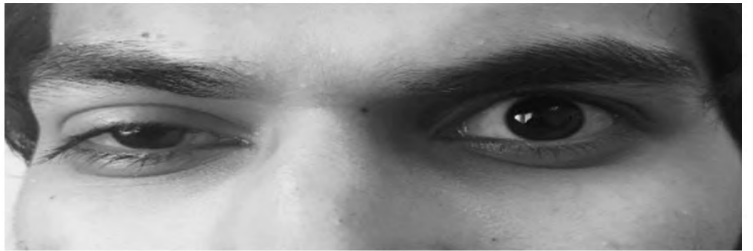

Improved RT proptosis at hospital discharge

Case (2): Male patient, 22 years, presented with post traumatic direct CCF with extensive carotid tear and severe cortical venous reflux in addition to proptosis. BOT showed good collateral supply and ICA occlusion proximal to ophthalmic A was done first to isolate fistula and avoid steal then occlusion of fistula with ICA was done.

\section{Treatment results:}

In 12 patients (100\%) complete obliteration of the CCF was achieved at control angiogram at the end of the procedure. ICA was preserved in 9 patients $(75 \%)$ while carotid occlusion in addition was done in 3 patients $(25 \%)$. In these 3 patients preservation of ICA was not feasible due to extensive traumatic vessel wall damage. These 3 patients were among patients passed BTO.

Classic triad of exophthalmos, chemosis, and bruit improved rapidly after successful obliteration 
of CCF and total improvement achieved in all patients after 3 months (100\%). Ophthalmoplegia and decreased visual acuity may take longer to resolve. Tow patients with blindness of the affected side did not show any improvement.

Good outcome (GOS 5) achieved in all patients without permanent morbidity or mortality. Apart from small groin hematoma in 1 patient no procedural complications in our series.

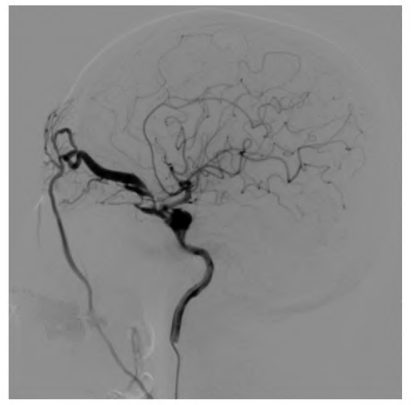

LT ICA LAT pre

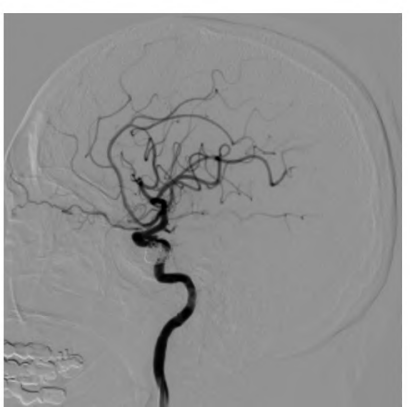

LT ICA LAT post

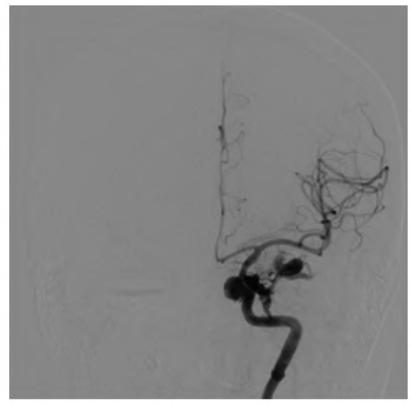

LT ICA AP pre

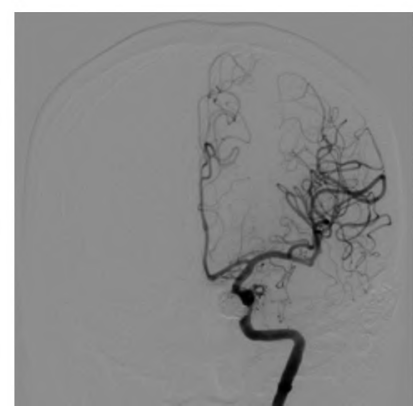

LT ICA AP post

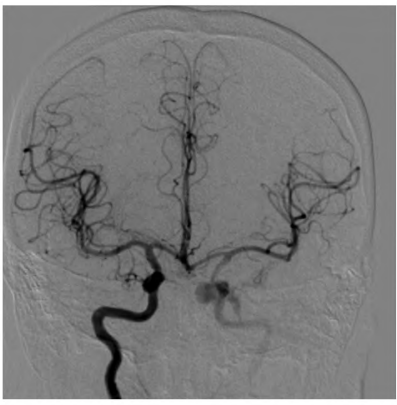

RT ICA AP (BOT)

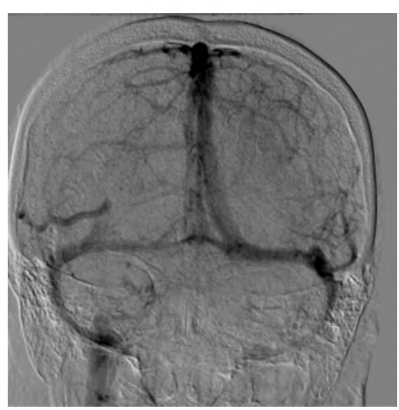

RT ICA AP (BOT)

Venous phase

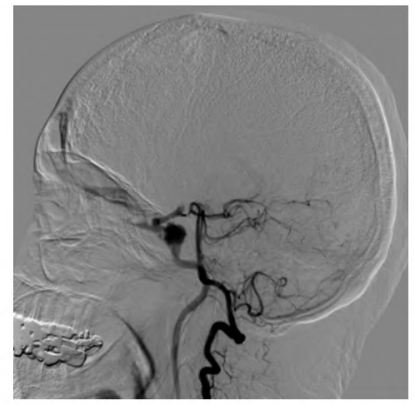

LT VA LAT (BOT)

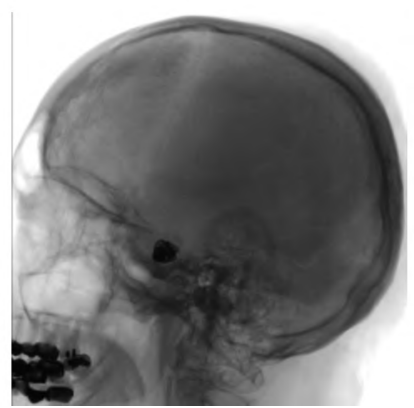

Fluoroscopic image LAT (coil mass)

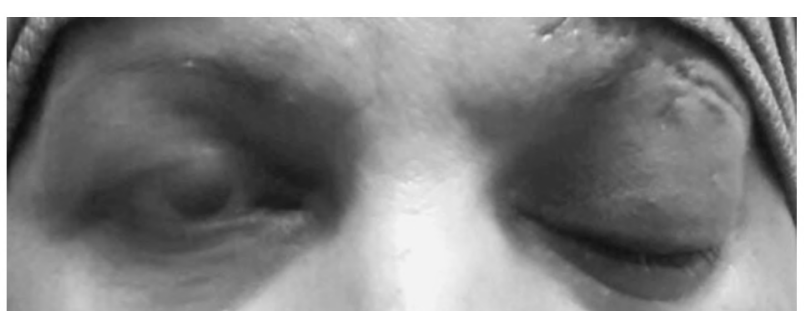

LT proptosis pre-operative

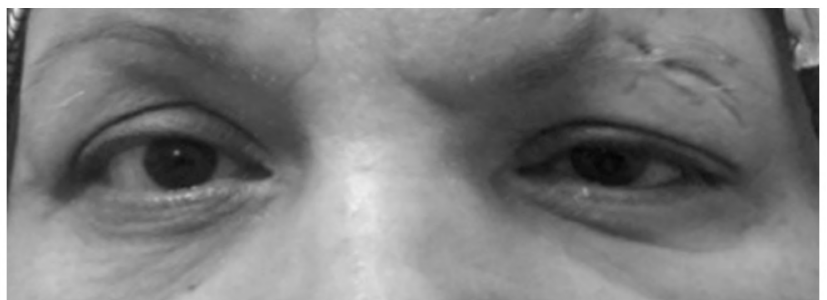

Improved LT proptosis 3 months post-operative

Case (3): Female patient, 60 years old presented with post traumatic direct CCF and proptosis. BTO was done and revealed good collateral supply. Occlusion of fistula with ICA preservation was done. 


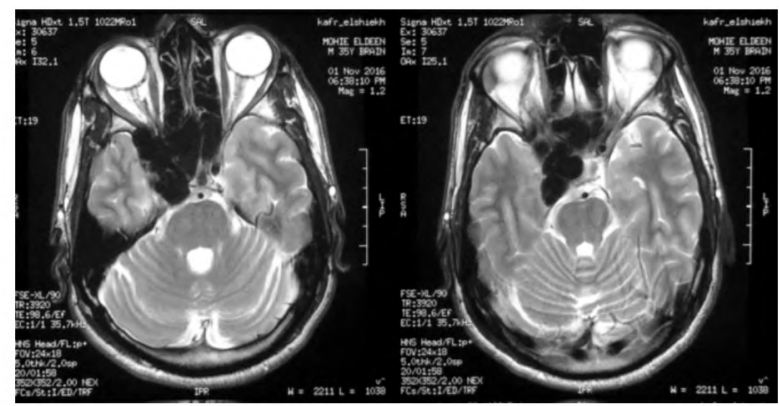

Axial T2 show dilated cavernous sinus on RT side \& dilated RT superior ophthalmic vein
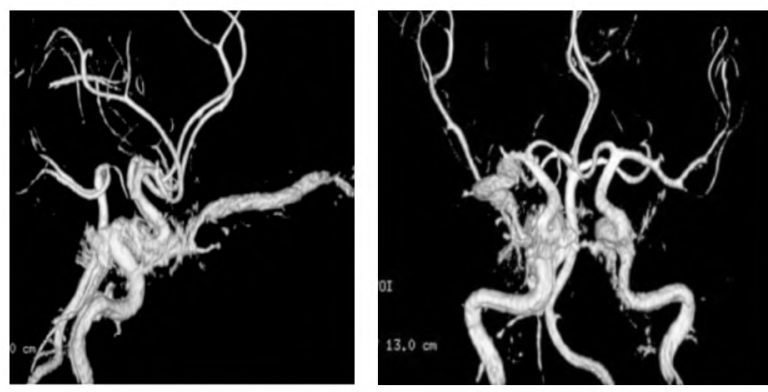

MRA shows CCF

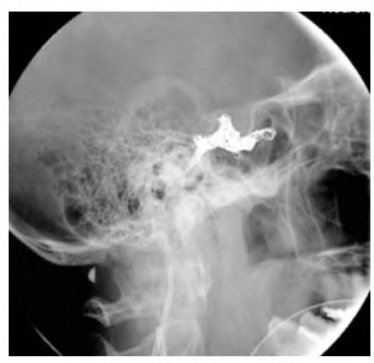

Fluoroscopic image AP (coil mass)

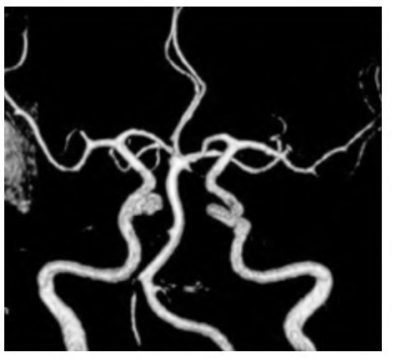

MRA show occlusion of CCF with ICA sparing

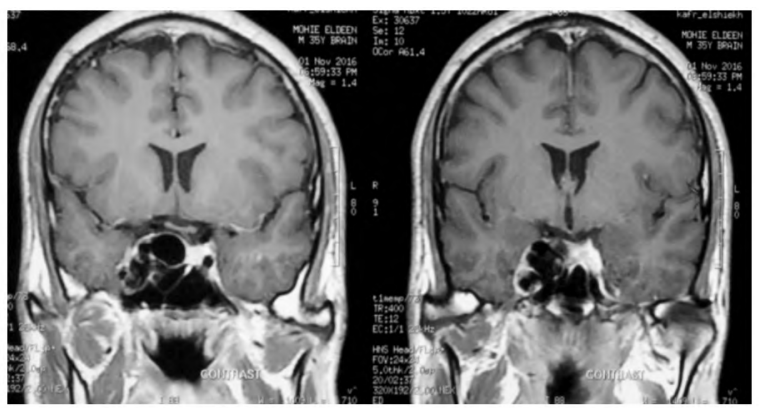

Coronal T1 show dilated cavernous sinus spaces on RT side

Case (4): Male patient, 55 years old, presented with direct CCF and RT side proptosis. Occlusion of fistula with ICA sparing done and confirmed by MRA at hospital discharge.

\section{Discussion}

Treatment options for CCF include manual compression; surgical management; stereotactic radiosurgery; and endovascular repair via a transarterial or trans-venous route with or without ICA sacrifice [5]. Recent advances in the endovascular technology have enabled this mode of treatment to be a primary treatment option [10]. Trans-venous approach is preferred for indirect CCF while transarterial approach is preferred for direct CCF [11].

Trans-arterial approach include use of detachable balloons, coils, covered stents and ICA sacrifice if needed [7]. Transarterial balloon detachment was the endovascular treatment of choice for direct CCF [12]. Limitations to use of balloons include; premature detachment, deflation, migration, punc-

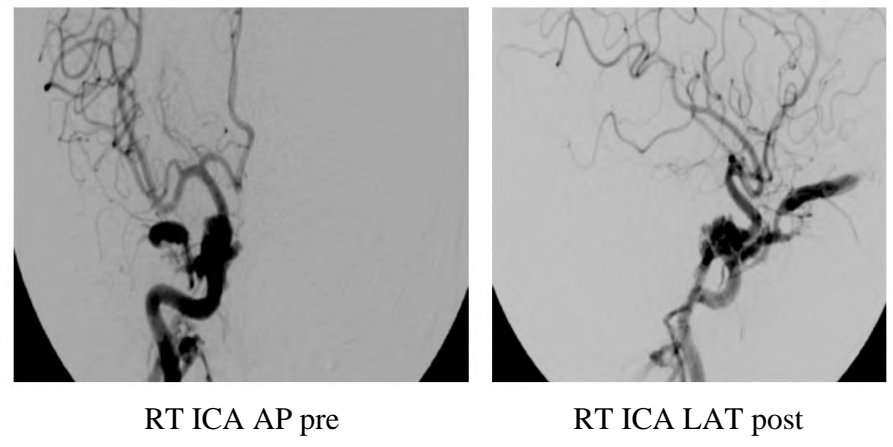

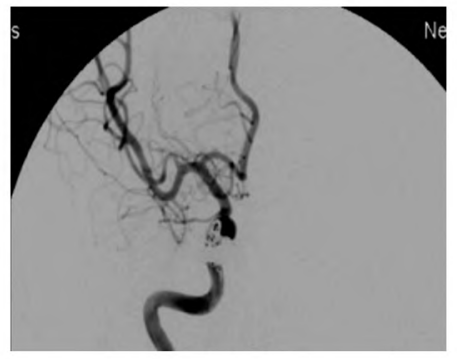

RT ICA AP post

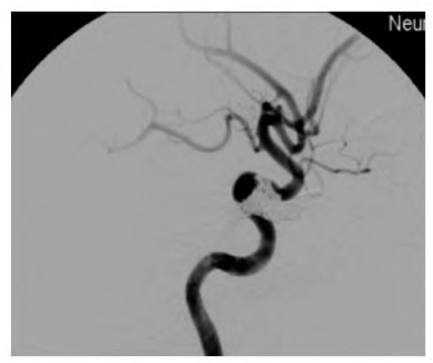

RT ICA LAT post ture of the balloon by bony fragments, small size of the fistula and pseudo aneurysm formation [13]

Due to disadvantages of balloons, use of coils become more popularized in occlusion of CCF. Advantages of coils include easy access, control, adjustment, deployment, retrieval, reposition in addition to availability of different thickness, sizes, lengths, shapes [14]. Main disadvantages of coils include mainly high cost, sometimes compaction and rarely migration [4].

In our series, occlusion rate was achieved in all patients (100\%) while ICA preservation was achieved in $75 \%$ of patients. Higashida achieved $99 \%$ occlusion rate and ICA patency in $88 \%$ in his series [15]. Gupta achieved $86 \%$ occlusion rate and ICA patency in $98 \%$ [16]. 
Extensive ICA tears in our series explain difference in ICA occlusion rate with other series. Gemmete described occlusion of ICA and fistula as well as the only valid option in cases with extensive ICA tears [7]. Debrun reported need for ICA occlusion in $20 \%$ of type A CCF [17] . No procedural morbidity or mortality in our series. Worsening of occlumotor palsy and ICA occlusion were the main complications in other series [13].

\section{Conclusion:}

Endovascular treatment (either trans-arterial or trans-venous) is the main line of treatment of CCF. Tran-venous approach is the preferred for indirect CCF. Transarterial approach by using coils or balloons is preferred for direct CCF. Coils now superior to balloons due to many advantages including easy access, control, adjustment, deployment, retrieval, reposition in addition to availability of different thickness, sizes, lengths, shapes main disadvantages of coils include mainly high cost, sometimes compaction and rarely migration. Still more refinements in coils designs needed to avoid such disadvantages.

\section{References}

1- BARROW D.L., et al.: Classification and treatment of spontaneous carotid-cavernous sinus fistulas. J. Neurosurg., 62 (2): p. 248-56, 1985

2- VAN ROOIJ W.J., M. SLUZEWSKI and G.N. BEUTE: Ruptured cavernous sinus aneurysms causing carotid cavernous fistula: Incidence, clinical presentation, treatment, and outcome. AJNR Am. J. Neuroradiol., 27 (1): p. 185-9, 2006.

3- HALBACH V.V., et al.: Carotid cavernous fistulae: Indications for urgent treatment. AJR Am. J. Roentgenol., 149 (3): p. 587-93, 1987.

4- BINK A., et al.: Long-term outcome after coil embolization of cavernous sinus arteriovenous fistulas. AJNR Am. J. Neuroradiol., 31 (7): p. 1216-21, 2010.

5- LU X., et al.: A comparison of different transarterial embolization techniques for direct carotid cavernous fistulas: A single center experience in 32 patients. J. Vasc. Interv. Neurol., 7 (5): p. 35-47, 2014.

6- SERBINENKO F.A.: Balloon catheterization and occlusion of major cerebral vessels. J. Neurosurg., 41 (2): p. 125 45, 1974.

7- GEMMETE J.J., S.A. ANSARI and D.M. GANDHI: Endovascular techniques for treatment of carotidcavernous fistula. J. Neuroophthalmol., 29 (1): p. 62-71, 2009.

8- De KEIZER R.: Carotid-cavernous and orbital arteriovenous fistulas: Ocular features, diagnostic and hemodynamic considerations in relation to visual impairment and morbidity. Orbit., 22 (2): p. 121-42, 2003.

9- HIRABUKI N., et al.: MR imaging of dural arteriovenous malformations with ocular signs. Neuroradiology, 30 (5): p. $390-4,1988$.

10- KUPERSMITH M.J., et al.: Management of nontraumatic vascular shunts involving the cavernous sinus. Ophthalmology, 95 (1): p. 121-30, 1988.

11- BARNWELL S.L. and O.R. O'NEILL: Endovascular therapy of carotid cavernous fistulas. Neurosurg. Clin. N. Am., 5 (3): p. 485-95, 1994.

12- TENG M.M., et al.: Double-balloon technique for embolization of carotid cavernous fistulas. AJNR Am. J. Neuroradiol., 21 (9): p. 1753-6, 2000.

13- LEWIS A.I., T.A. TOMSICK and J.M. TEW Jr.: Management of 100 consecutive direct carotid-cavernous fistulas: Results of treatment with detachable balloons. Neurosurgery, 36 (2): p. 239-44; discussion 244-5, 1995.

14- HALBACH V.V., et al.: Transarterial platinum coil embolization of carotid-cavernous fistulas. AJNR Am. J. Neuroradiol., 12 (3): p. 429-33, 1991.

15- HIGASHIDA R.T., et al.: Interventional neurovascular treatment of traumatic carotid and vertebral artery lesions: Results in 234 cases. AJR Am. J. Roentgenol., 153 (3): p. 577-82, 1989.

16- GUPTA A.K., et al.: Endovascular treatment of direct carotid cavernous fistulae: A pictorial review. Neuroradiology, 48 (11): p. 831-9, 2006.

17- DEBRUN G.M., et al.: Indications for treatment and classification of 132 carotid-cavernous fistulas. Neurosurgery, 22 (2): p. 285-9, 1988. 


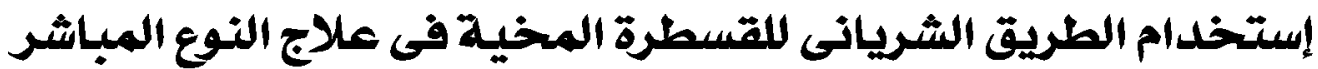

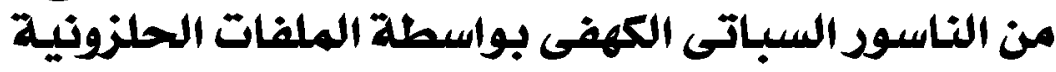

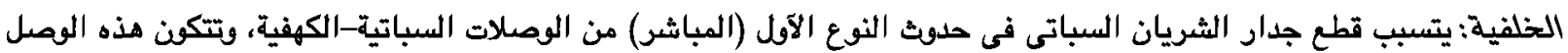

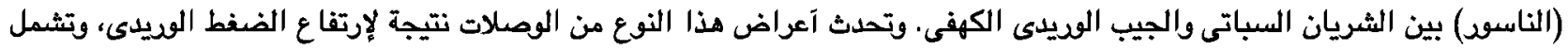

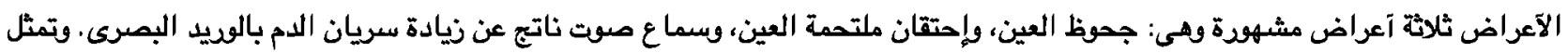

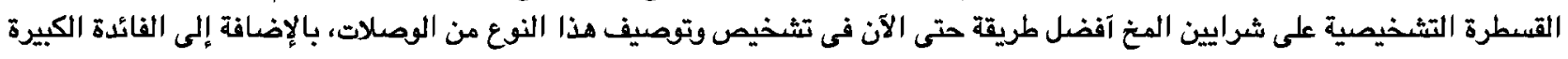
فى التخطيط للتدخل لعلاج هذه الوصلات. ويشمل علاج هذه الوصلات التدخل بالقسطرة العلاجية لغلق الوصلة.

الهدف: تهدف هذه الدراسة إلى تقييم كفاءة وسلامة إستخدام الطريق الشريانى للقسطرة المخية مع إستخدام الملفات فى الحلزنينية فى

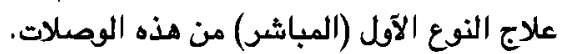

الطرق: تمت هذه الدراسة على جميع الحالات التى تعانى من النوع المباشر من الناسقد السباتى الكهفى بقسم جراحة المخ والآعصاب

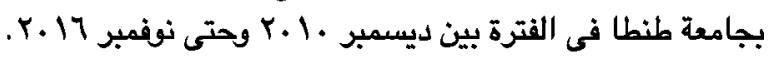

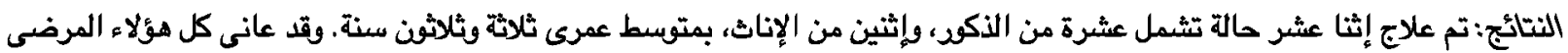

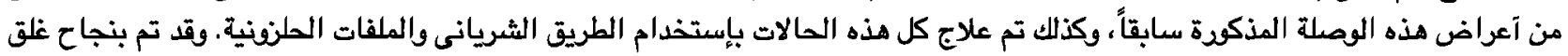

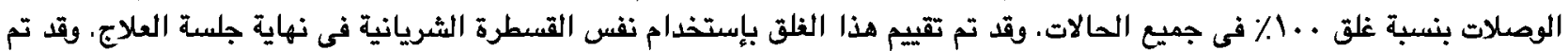

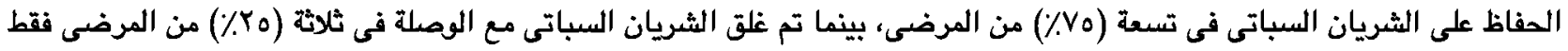

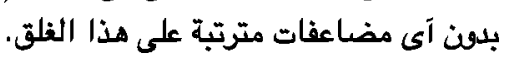

الإستتاجات: إستخدام الطريق الشريانى للقسطرة المخية فى علاج النوع المباشر من الناسود السباتى الكهفى بواسطة الملفات الحلزونية هو وسيلة آمنة وفعالة اللغاية فى علاج هذا النقات النورانع من الحالات. 